\title{
Superior mediastinal obstruction with aortic dissection after aortic valve replacement Diagnosis by computed tomography
}

\author{
D L STONE, M C PETCH, G I VERNEY, A K DIXON \\ From the Departments of Cardiology and Radiology, Papworth Hospital and Addenbrooke's Hospital, Cambridge
}

SUMMARY In two patients aortic dissection occurred as a late complication of aortic valve replacement and caused superior vena caval obstruction. The dissection and superior vena caval obstruction were diagnosed by computed tomography.

In recent years, computed tomography has been increasingly used in the diagnosis of diseases of the heart and thorax. ${ }^{12}$ We report two patients who presented with superior mediastinal obstruction late after aortic valve replacement. Computed tomography with contrast enhancement was able to show both the venous compression and its cause, aortic dissection.

\section{Patients and methods}

\section{CASE 1}

A 70 year old man had an aortic valve replacement with a $25 \mathrm{~mm}$ Carpentier-Edwards prosthesis for aortic regurgitation with congestive cardiac failure in February 1978. The postoperative recovery was complicated by cardiac tamponade due to a small aortic tear near a stitch hole. Histological examination of a removed portion of the aorta was normal.

He remained well until January 1982 when he noticed increasing breathlessness after he stopped taking atenolol for longstanding hypertension. This was restarted and he was again asymptomatic until 9 March 1982 when he presented with a one week history of frontal headaches, which were worse on lying down. For one day he had noticed swelling of his face, which was worse when he awoke in the morning. On examination he had swelling of the face, dilated jugular veins, and an ejection systolic murmur. All pulses were present and palpable. An electrocardiogram still showed a right bundle branch block pattern and a

Requests for reprints to Dr DL Stone, Regional Cardiac Unit, Papworth Hospital, Papworth Everard, Cambridge CB3 8RE

Accepted for publication 5 January 1984 chest $x$ ray film a dilated but unchanged ascending aorta. A clinical diagnosis of superior mediastinal obstruction was made, and computed tomography with contrast enhancement performed on 18 March 1982 showed the dilated ascending aorta with clear evidence of dissection. Flow of contrast via the azygos system was also clearly seen. In view of his age and the extensiveness of any surgery that might be required his medical treatment was continued. The signs of mediastinal obstruction subsided, and he is alive one year after the episode although he remains breathless on moderate exertion.

\section{CASE 2}

This patient first presented aged 51 years with a history of exertional presyncope and orthopnoea. He was found to have aortic stenosis.and in July 1979 underwent aortic valve replacement with a $25 \mathrm{~mm}$ BjörkShiley valve. The ascending aorta had an aneurysmal dilatation. He was discharged after an uneventful postoperative period and remained well until 6 November 1982, when he was admitted with sudden syncope following micturition and a sharp pain over the chest, radiating to the throat, which he attributed to having fallen awkwardly. A chest $x$ ray film again showed an aneurysmal dilatation of the aorta.

Twelve days later chest pain recurred, and he subsequently developed progressive right facial swelling. There was no change in his heart sounds, $x$ ray film, or electrocardiogram but computed tomography with contrast enhancement showed a dissection in the proximal portion of the ascending aorta and compression of the superior vena cava. Flow of contrast via the azygos system was clearly seen. The extent and location of the dissection were confirmed by contrast angiography. He underwent replacement of the 


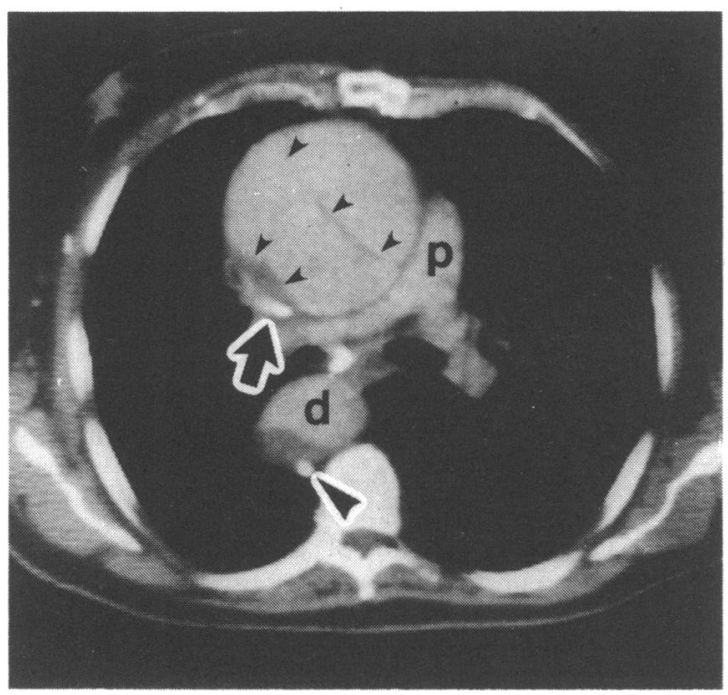

Fig. 1 Case 1: computed tomogram showing three lumina in the ascending aorta; the interluminal flaps are marked by small arrowheads, with evidence of flattening and compression of the superior vena cava (large arrow) and pulmonary artery (p). The enhanced azygos vein is clearly seen (large arrowhead). There are two distinct lumina in the descending aorta (d) with differential uptake of contrast showing the distal extension of the dissection.

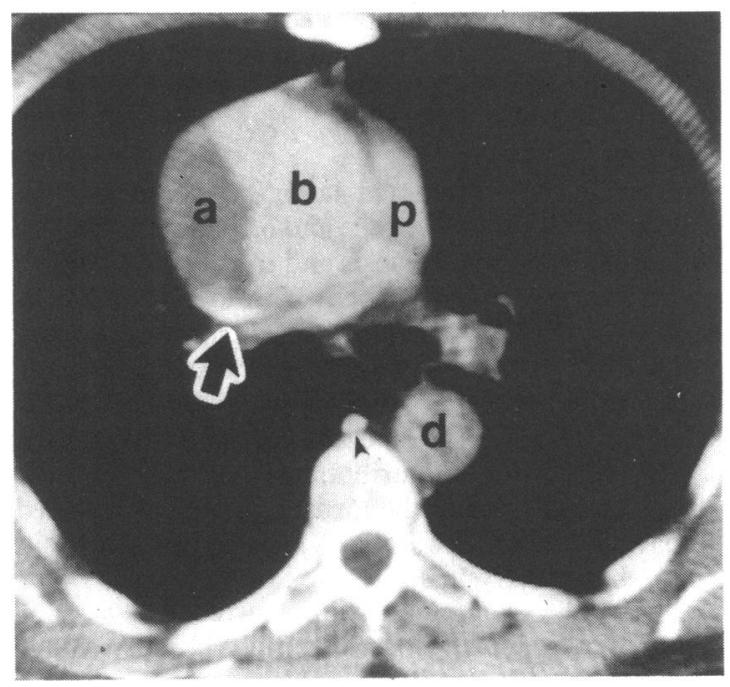

Fig. 2 Case 2: computed tomogram clearly showing the ascending aorta with two distinct lumina $(a, b)$. There is differential uptake of contrast but it is impossible to define which is the "true" and which is the "false" lumen. The superior vena cava (large arrow) appears to be compressed by the ascending aorta, as does the pulmonary artery (p). The small arrow shows contrast in the arygos vein. There is no evidence of the dissection involving the descending aorta (d). ascending aorta and coronary bypass surgery and was discharged to follow up.

\section{COMPUTED TOMOGRAPHY}

The patients were investigated with a Siemens Somatom 2 machine (scan time $5 \mathrm{~s}$ ). Two series of scans were performed, the first to decide at which level the contrast enhanced studies should be performed. Fifty millilitres of Conray 420 were then injected as a bolus into a large peripheral vein and the series of contrast enhanced scans started approximately $10 \mathrm{~s}$ after the start of the injection. Fig. 1 shows the scan from case 1 and Fig. 2 that from case 2.

\section{Discussion}

Computed tomography has recently been used in the diagnosis of diseases of the heart, pericardium, and thorax..$^{-5}$ It is able to identify an intracardiac thrombus $^{6}{ }^{7}$ and patent coronary artery bypass grafts. ${ }^{8}$ In particular it has been used with success in the diagnosis and follow up of aortic dissection. ${ }^{9-13}$ Dissection of the aorta is unusual after aortic valve replacement, and superior mediastinal obstruction is an accepted albeit uncommon complication of dissection. ${ }^{14}$ These two cases are noteworthy because of the concurrence of the two events and the success of computed tomography in making the diagnosis. This proved to be the ideal method of investigation since it provided information about the anatomy of different intrathoracic structures with minimal discomfort to the patient. In both cases the presence of two or more lumina with differential uptake of contrast made the diagnosis certain clinically, and in the second a luminal flap was seen with contrast on either side. The scans show the value of computed tomography in defining the site and extent of the dissection; in case 1 the findings were confirmed by angiography.

The site of vena caval compression was defined precisely, and in both cases definite enhancement of the azygos vein showed the collateral venous circulation. There are no previous reports of this condition being identified by computed tomography. Doppman et al, however, described dilatation of the inferior vena cava in constrictive pericardial disease but found that the superior vena caval dilatation was not a notable clinical finding even in the presence of clinical venous distension. ${ }^{15}$

Thus computed tomography has been shown to provide clear evidence of the site and cause of superior mediastinal compression. It should prove valuable in the initial assessment of patients with suspected dissection, particularly in the presence of other abnormalities or complications. 
We thank Dr D W Evans, Dr H A Fleming, Mr T A H English, and Mr B B Milstein for allowing us to present their cases and Mrs J Lawrence, research radiographer, for her help with computed tomography.

\section{References}

1 Brundage BH, Lipton MJ. The emergence of computed tomography as a cardiovascular diagnostic technique. Am Heart f 1982; 103: 313-6.

2 Heitzman ER. Computed tomography of the thorax: current perspectives. AYR 1981; 136: 3-12.

3 Moncada $\mathbf{R}$, Baker M, Salinas $M$, et al. Diagnostic role of computed tomography in pericardial heart disease: congenital defects, thickening, neoplasms, and effusions. Am Heart ff 1982; 103: 263-82.

4 Wong BYS, Lee KR, MacArthur RI. Diagnosis of pericardial effusion by computed tomography. Chest 1982; 81: 177-81.

5 Baron RL, Levitt RG, Sagel SS, Stanley RJ. Computed tomography in the evaluation of mediastinal widening. Radiology 1981; 138: 107-13.

6 Tomoda H, Hoshiai M, Furuya H, Shotsu A, Ootaki M, Matsuyama S. Evaluation of left ventricular thrombus with computed tomography. Am $\mathcal{f}$ Cardiol 1981; 48: 573-7.
7 Tomoda H, Hoshiai M, Tagawa R, et al. Evaluation of left atrial thrombus with computed tomography. Am Heart f 1980; 100: 306-10.

8 Kahl FR, Wolfman NT, Watts LE. Evaluation of aortocoronary bypass graft status by computed tomography. Am f Cardiol 1981; 48: 304-10.

9 Moncada R, Churchill R, Reynes C, et al. Diagnosis of dissecting aortic aneurysm by computed tomography. Lancet 1981; i: 238-41.

10 Godwin JD, Herfkens RL, Skiöldebrand CG, Federle MP, Lipton MJ. Evaluation of dissections and aneurysms of the thoracic aorta by conventional and dynamic CT scanning. Radiology 1980; 136: 125-33.

11 Lardé D, Belloir C, Vasile N, Frija J, Ferrané J. Computed tomography of aortic dissection. Radiology 1980; 136: 147-51.

12 Gross SC, Barr I, Eyler WR, Khaja F, Goldstein S. Computed tomography in dissection of the thoracic aorta. Radiology 1980; 136: 135-9.

13 Godwin JD, Turley K, Herfkens RJ, Lipton MJ. Computed tomography for follow up of chronic aortic dissections. Radiology 1981; 139: 655-60.

14 Cohn PF, Braunwald E. Traumatic heart disease. In: Braunwald E, ed. Heart disease. Philadelphia: WB Saunders, 1980: 1583-632.

15 Doppman JL, Rienmuller R, Lissner J, et al. Computed tomography in constrictive pericardial disease. $f$ Comput Assist Tomogr 1981; 5: 1-11. 